\title{
Experiment and Simulation Verification on the Composite Mode of Enhanced Glulam
}

\author{
Zhongfeng Zhang ${ }^{1}$, Kai Huang ${ }^{2}$ and Xianyan Zhou ${ }^{3, *}$ \\ ${ }^{1,2,3}$ College of Furniture, Central South University of Forestry and Technology - Changsha - China
}

Received 15 May 2013; Accepted 25 July 2013

\begin{abstract}
The structural glulam used in bridge engineering is huge, which exists many defects by full-scale experimental method to research its relevant properties. Both experiment and simulation verification of ABAQUS were carried to forecast the enhanced composite structure and to reveal the composite enhancement effect of glulam made up of plantation eucalyptus veneers with the reinforced materials of fiberglass mesh and aluminium foil, and the basic mechanical properties were viewed as the evaluation index. The results show that the simulation model is feasible and rational to be applied to choose the better composite mode, and the best enhanced composite structure of glulam is the central seven layers eucalyptus veneers with criss-cross assembling structure, the outer three layers eucalyptus veneers with parallel assembling structure and fiberglass mesh and aluminum foil interval distributed among every two veneers.
\end{abstract}

Keywords: Enhanced Glulam, Abaqus, Fiberglass Mesh, Aluminum Foil, Composite Mode, Mechanical Properties, Simulation Model

\section{Introduction}

Glulam is a kind of high quality material applied in bridge engineering and its enhanced composite mode and mechanics evaluation has always been the hot research topic $[1,2,3]$. Researchers devoted to confirm the performance on each part of timber bridges which were build in the late 1960s and early 1970s [1,4], Hurlbut and Davids discussed the property of timber as a structure material used in highway bridge $[5,6]$; Bakht analyzed the load distribution of plane laminated timber deck in highway bridge [7]; Hasebe, etc. researched the behavior of using the glued laminated timber as the steel beam of a bridge [8]; Morison discussed the structural integrity of wood bridge [9]; Gutkowski, etc. achieved the laboratory load testing of wood bridge.Burgers [10]; Burgers, etc. evaluated large scale wood bridge by shear peak [11]; Serrano established the nonlinearity three-dimensional finite element model and discussed the theory parameters of timberwork [12]. As mentioned, there is no research on the enhanced composite mode of glulam made up of wood veneers with the reinforced materials of fiberglass mesh and aluminium foil. However, fiberglass is an excellent inorganic nonmetallic material with good insulation and corrosion resistance, strong heat-resistant and also high mechanical strength, which is always used in composites [13,14,15]. And aluminum foil is a sort of soft metallic film with graceful silver luster, which is not only dampproof, airtight, shading, corrosion resisting, fragrance-holding, non-toxic and tasteless, but also easily processed out kinds of beautiful designs and patterns to be a kind of favorite and perfect

\footnotetext{
*E-mail address: csfuzhangzf@163.com (The corresponding author) ISSN: 1791-2377 @ 2013 Kavala Institute of Technology. All rights reserved.
}

packaging material $[16,17,18]$. Therefore, this research aims at forecasting the enhanced composite structure and to reveal the composite enhancement effect of glulam made up of plantation eucalyptus veneers with the reinforced materials of fiberglass mesh and aluminium foil by the experiment and simulation verification of ABAQUS with the evaluation index of basic mechanical properties, which will provide the scientific guide for the plantation wood widely in the field of bridge engineering.

\section{Materials and Methods}

\subsection{Materials and Methods Experimental Materials}

Plantation Eucalyptus Wood Veneer: The size is $1.27 \mathrm{~m} \times 0.64 \mathrm{~m} \times 1.3 \mathrm{~mm}$, the density is about $0.61 \mathrm{~g} / \mathrm{cm} 3$ and the moisture content is $5 \%-8 \%$.

Aluminum Foil: The thickness is $0.05 \mathrm{~mm}$, the type is aluminum alloy 1060 , the density is $2.71 \mathrm{~g} / \mathrm{cm} 3$, the tensile strength $\geq 75 \mathrm{MPa}$ and the offset yield strength $\geq 35 \mathrm{MPa}$.

Two-component Epoxy Adhesive: The A component is milky white or gray white sticky liquid, The $\mathrm{B}$ component is yellow-brown or red-brown sticky liquid, applicable period is 1 hour $\left(25^{\circ} \mathrm{C}\right)$, the curing speed is $2.5-3.5 \mathrm{~h}\left(25^{\circ} \mathrm{C}\right)$ and the tensile shear strength $\geq 8 \mathrm{MPa}\left(25^{\circ} \mathrm{C} \times 48 \mathrm{~h}\right)$.

Fiberglass Mesh: plain weave, the warp and weft density are $128 \times 68$.

\subsection{Design Proposals of Specimens}

Design proposals of specimens were shown in Table (1). 3 parallel specimens in each test group and 5 test groups in total. The enhanced effect of fiberglass mesh was obtained through the comparison of group $1 \mathrm{~A} / 2 \mathrm{~A} / 3 \mathrm{~A} / 5 \mathrm{~A}$, and the enhanced effect of aluminum foil was obtained through the comparison of group $1 \mathrm{~A} / 2 \mathrm{~A} / 4 \mathrm{~A} / 5 \mathrm{~A}$. 
Table 1: Design proposals of specimens

\begin{tabular}{|c|c|}
\hline $\begin{array}{c}\text { Test } \\
\text { Group }\end{array}$ & Assembling pattern \\
\hline $1 \mathrm{~A}$ & $\begin{array}{l}\text { The central seven layers veneers with criss-cross } \\
\text { assembling structure, the outer three layers veneers } \\
\text { with paralleled assembling structure. }\end{array}$ \\
\hline $2 \mathrm{~A}$ & $\begin{array}{l}\text { The central seven layers veneers with criss-cross } \\
\text { assembling structure, the outer three layers veneers } \\
\text { with paralleled assembling structure, and fiberglass } \\
\text { mesh placed every two veneers making up one half } \\
\text { of the glulam and aluminum foil placed every two } \\
\text { veneers making up the other half. }\end{array}$ \\
\hline $3 \mathrm{~A}$ & $\begin{array}{l}\text { The central seven layers veneers with criss-cross } \\
\text { assembling structure, the outer three layers veneers } \\
\text { with paralleled assembling structure, and fiberglass } \\
\text { mesh placed every two veneers making up the } \\
\text { glulam. }\end{array}$ \\
\hline $4 \mathrm{~A}$ & $\begin{array}{l}\text { The central seven layers veneers with criss-cross } \\
\text { assembling structure, the outer three layers veneers } \\
\text { with paralleled assembling structure, and aluminum } \\
\text { foil placed every two veneers making up the } \\
\text { glulam. }\end{array}$ \\
\hline $5 \mathrm{~A}$ & $\begin{array}{l}\text { The central seven layers veneers with criss-cross } \\
\text { assembling structure, the outer three layers veneers } \\
\text { with paralleled assembling structure, and fiberglass } \\
\text { mesh and aluminum foil interval distributed among } \\
\text { every two veneers making up the glulam. }\end{array}$ \\
\hline
\end{tabular}

specimens were put into the cold press with the air temperature about $20^{\circ} \mathrm{C}$, and then to be pressurized to $4 \mathrm{MPa}$ quickly and to be maintained for 1 hour, then the power source was turned off and the press-holding time was $23 \mathrm{~h}$. The sectional area of obtained specimens was $350 \times 350 \mathrm{~mm}$. The normal section of the Glulam was showed in Fig.1. The standard specimens were made and tested according to "Standard for Methods testing of Timber Structures" (GB/T 50329-2002) and "Plywood" (GB 9846-2004). The specimens for Testing MOR and MOE: Length $\times$ Width $=300$ $\mathrm{mm} \times 50 \mathrm{~mm}$, they were loaded to failure at the rate of $10 \mathrm{~Pa} / \mathrm{s}$ and the loading methods were consulted "Test methods of evaluating the properties of wood-based panels and surface decorated wood-based panels" (GB/T 17657-1999). Test with parallel loading and vertical loading was showed in Fig.2.

\subsection{Finite Element Analysis Proposal}

The ABAQUS software was applied to study on numerical simulation verification.

\section{Results and Analysis of the Test}

\subsection{Analysis of the Enhanced Composite Effect}

The average of 3 parallel specimens in each group was taken, and the total test results of 5 groups of specimens were shown in Table 2.

\subsection{Experimental Methods}

According to the assemble pattern in Table (1) to assemble the specimens with a double spread of $350 \mathrm{~g} / \mathrm{cm}^{2}$, then the

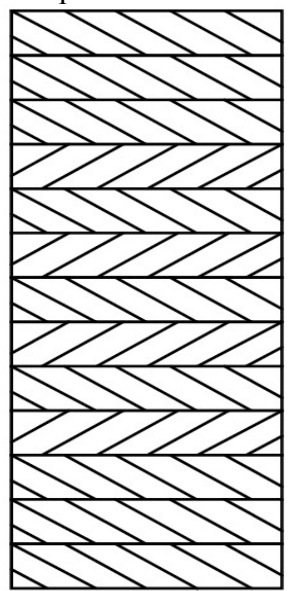

$1 \mathrm{~A}$

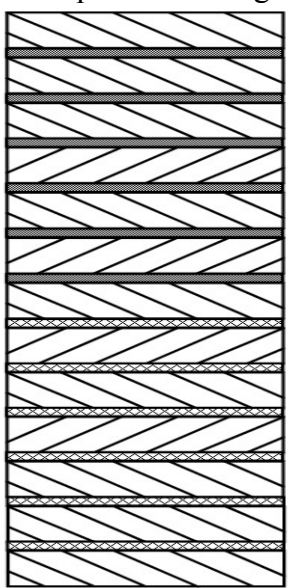

$2 \mathrm{~A}$

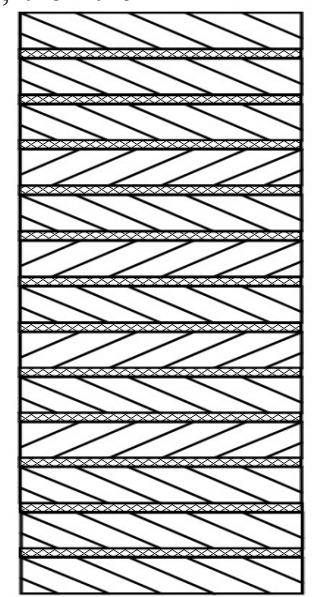

$3 \mathrm{~A}$

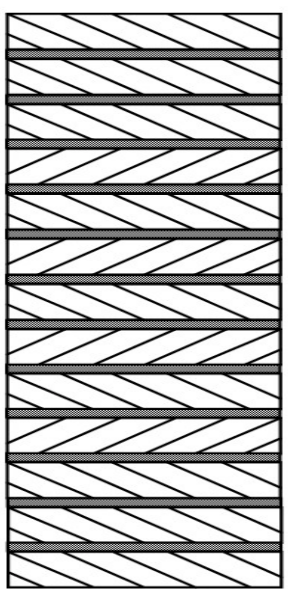

$4 \mathrm{~A}$

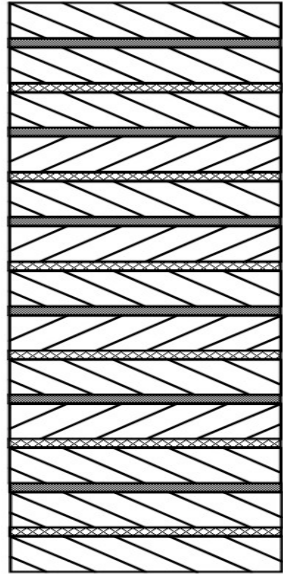

$5 \mathrm{~A}$

Fig.1. Normal section of the Glulam

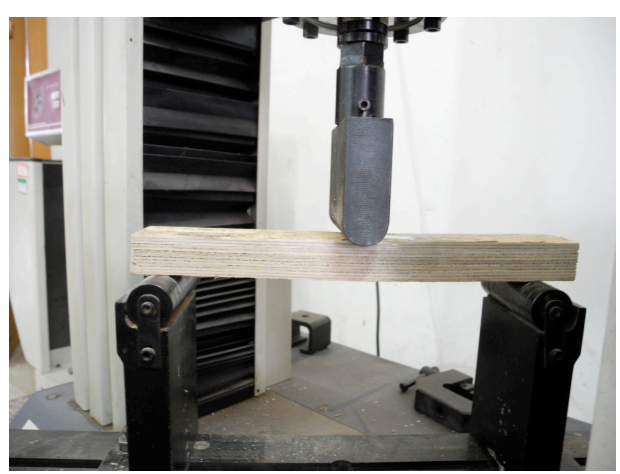

Vertical loading

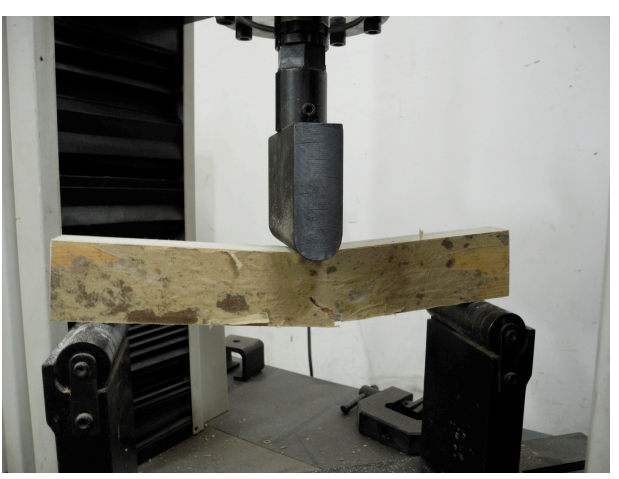

Parallel loading

Fig.2. Loading methods of the test

Table 2: Results of the testing 


\begin{tabular}{c|c|c|c|c|c|c|c|c|c|c}
\hline \multirow{2}{*}{$\begin{array}{c}\text { Test } \\
\text { group }\end{array}$} & $\begin{array}{c}\text { Width } \\
(\mathrm{mm})\end{array}$ & $\begin{array}{c}\text { Thickness } \\
(\mathrm{mm})\end{array}$ & $\begin{array}{c}\text { Fracture } \\
\text { load } \\
(\mathrm{N})\end{array}$ & $\begin{array}{c}\text { Modulus } \\
\text { of } \\
\text { rupture } \\
(\mathrm{MPa})\end{array}$ & $\begin{array}{c}\text { Modulus } \\
\text { of } \\
\text { elasticity } \\
(\mathrm{MPa})\end{array}$ & $\begin{array}{c}\text { Width } \\
(\mathrm{mm})\end{array}$ & $\begin{array}{c}\text { Thickness } \\
(\mathrm{mm})\end{array}$ & $\begin{array}{c}\text { Fracture } \\
\text { load } \\
(\mathrm{N})\end{array}$ & $\begin{array}{c}\text { Modulus } \\
\text { of } \\
\text { rupture } \\
(\mathrm{MPa})\end{array}$ & $\begin{array}{c}\text { Modulus } \\
\text { of } \\
\text { elasticity } \\
(\mathrm{MPa})\end{array}$ \\
\hline 1A & 50.60 & 27.46 & 1687 & 17.91 & 1770.6 & 26.68 & 50.46 & 7305 & 43.55 & 2627.0 \\
\hline 2A & 51.10 & 28.84 & 4555 & 43.40 & 3725.4 & 29.22 & 50.04 & 7920 & 43.84 & 2607.4 \\
\hline 3A & 50.72 & 27.70 & 4005 & 41.68 & 3811.5 & 28.30 & 52.90 & 9620 & 49.20 & 2948.2 \\
\hline 4A & 51.18 & 25.84 & 3560 & 42.19 & 4708.8 & 26.08 & 50.50 & 8050 & 49.02 & 3340.3 \\
\hline 5A & 51.14 & 25.16 & 4525 & 56.61 & 5407.1 & 25.48 & 50.64 & 9790 & 60.68 & 3658.4 \\
\hline
\end{tabular}

According to the data from the group of $1 \mathrm{~A} / 2 \mathrm{~A} / 3 \mathrm{~A} / 5 \mathrm{~A}$, the results showed that fiberglass mesh had the enhancement effect on glulam. The effect of Modulus of Rupture and Modulus of Elasticity was enhanced more than two times with the vertical loading method and the enhancement effect of single fiberglass mesh was the worst. What's more, the enhancement effect of fiberglass mesh on fracture load, Modulus of Rupture and Modulus of Elasticity were not obvious with the parallel loading method.

According to the data from the group of $1 \mathrm{~A} / 2 \mathrm{~A} / 4 \mathrm{~A} / 5 \mathrm{~A}$, the results showed that aluminum foil had the enhancement effect on glulam. The effect of Modulus of Rupture and Modulus of Elasticity was enhanced more than two times with the vertical loading method and the enhancement effect of single aluminum foil was the worst. What's more, the enhancement effect of aluminum foil on fracture load, Modulus of Rupture and Modulus of Elasticity were not obvious with the parallel loading method.

Aforementioned results and analysis showed the enhancement effect of fiberglass mesh and aluminum foil were not obvious with the parallel loading method. Besides, the enhancement effect of single fiberglass mesh or single aluminum foil was worse than their composite enhancement effect. At the same time, different assembling pattern of fiberglass mesh and aluminum foil resulted in different enhancement effect. Table 2 showed that the best assembling pattern was $5 \mathrm{~A}$ group which was the central seven layers eucalyptus veneers with criss-cross assembling structure, the outer three layers eucalyptus veneers with paralleled assembling structure and fiberglass mesh and aluminum foil interval placed among every two veneers.

\subsection{Finite Element Analysis and Verification of Glulam}

Verifying the rationality of specimen model and composite mode by comparison between the load and the deformation of the specimen in the whole test process with the specimen size and loading conditions same to the experiment. And the wood had the anisotropic characteristic while the other experimental materials were adopted isotropic characteristic.

(1) The project options of wood and epoxy adhesive

The anisotropic characteristic of wood: Young modulus of $E 1=E 2=E 3=10000 \mathrm{Mpa} ; \quad$ Poisson's ratio of NU12 $=$ NU13 $=0.4, \quad N U 23=0.04 ; \quad$ Shear modulus of $G 12=G 13=100, G 23=50$

The isotropic characteristic of epoxy adhesive: Young modulus of $E=1000000 \mathrm{Mpa}$, Shear modulus of $G 1=G 2=1000000$, Viscosity coefficient of $\mu=1.0 \times \mathrm{e}^{-5}$.
(2) Constitutive relation of fiberglass mesh showed in Fig.3.

The isotropic characteristic of fiberglass mesh: Young modulus of $E=7000 \mathrm{Mpa}$; Poisson's ratio of $N U=0.22$.

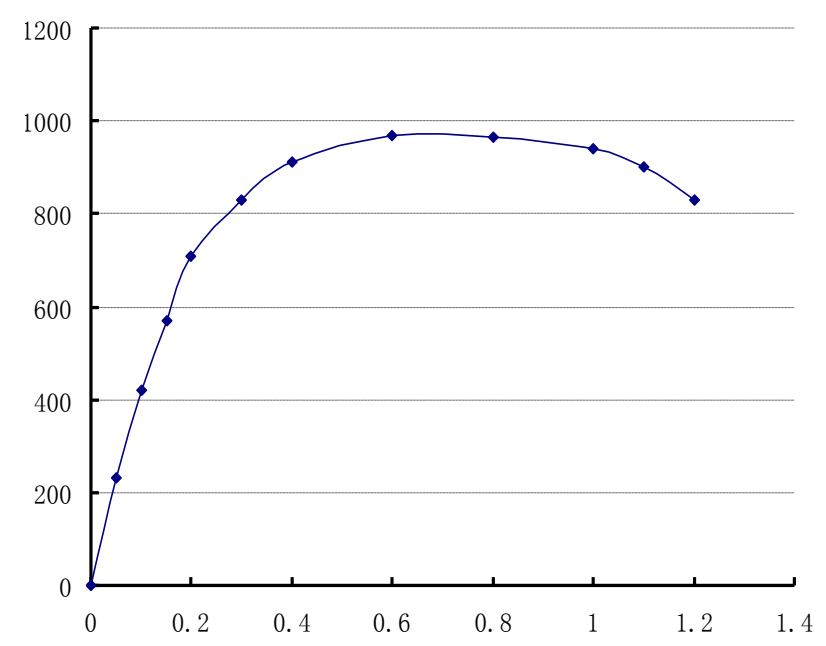

Fig. 3. The Constitutive relation of fiberglass mesh

(3) Constitutive relation of aluminum foil showed in Fig.4.

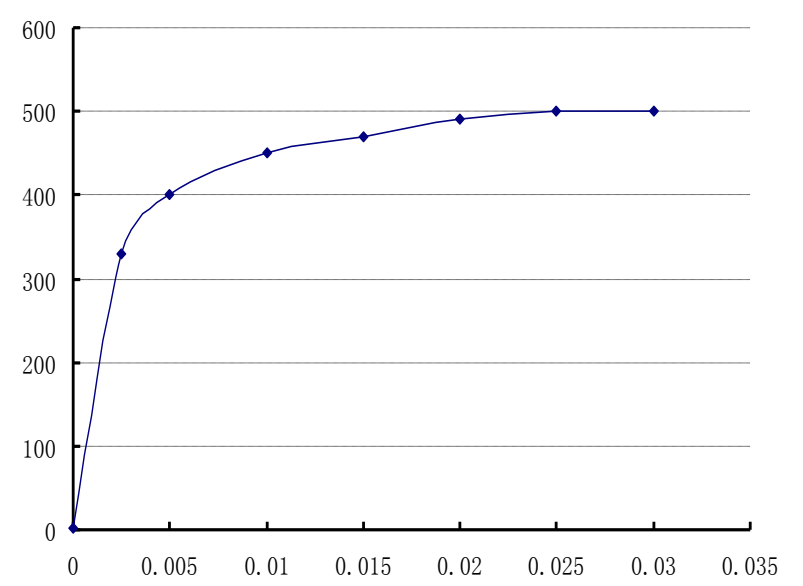

Fig. 4. The Constitutive relation of aluminum foil

As the damage of specimen mainly happened on stress concentration parts of mid-span and support point, the specimen model was divided into Five sections (in Fig.5), and the end and mid-span accounted for 1/10 of each specimen with thinner unit, while other parts with relative larger unit to improve the accuracy and speed of numerical analysis. 

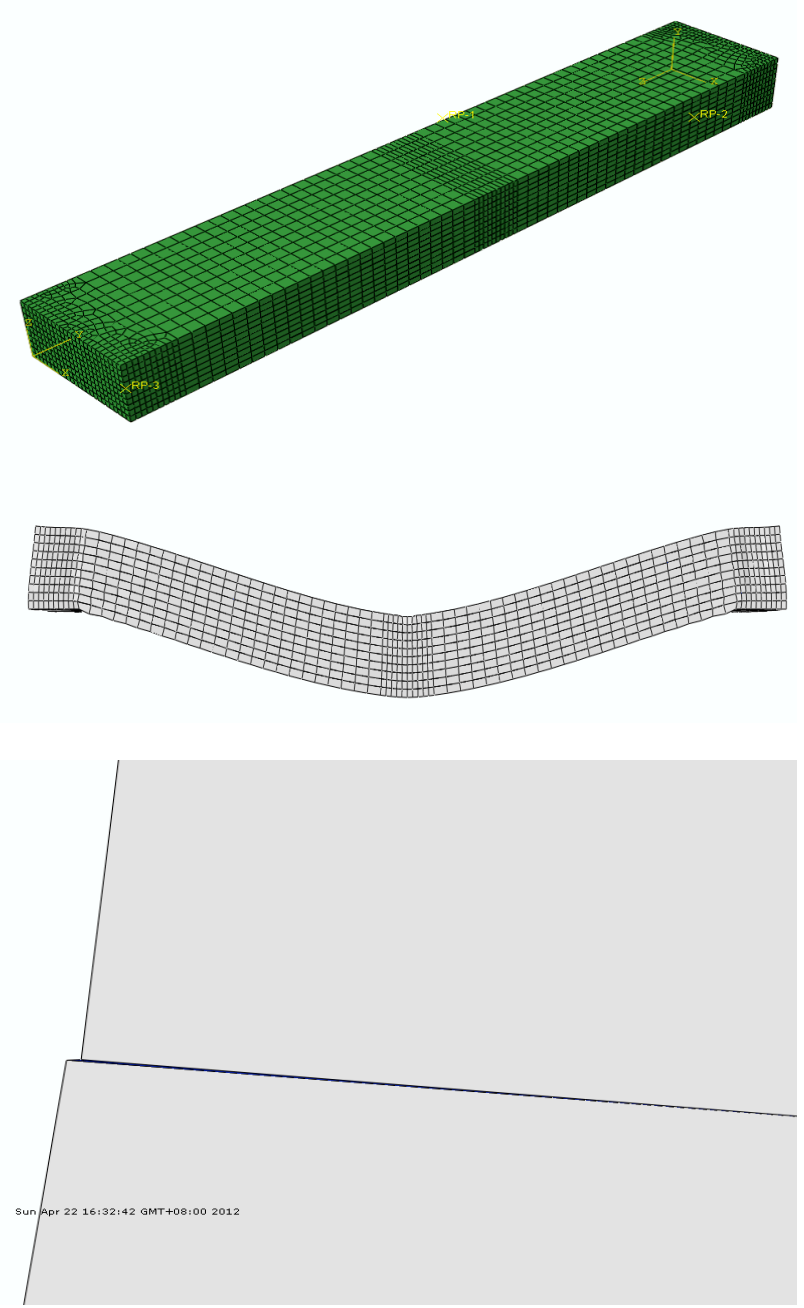

Fig.5. Component stress unit

(5) The comparison between experiment results and simulation results

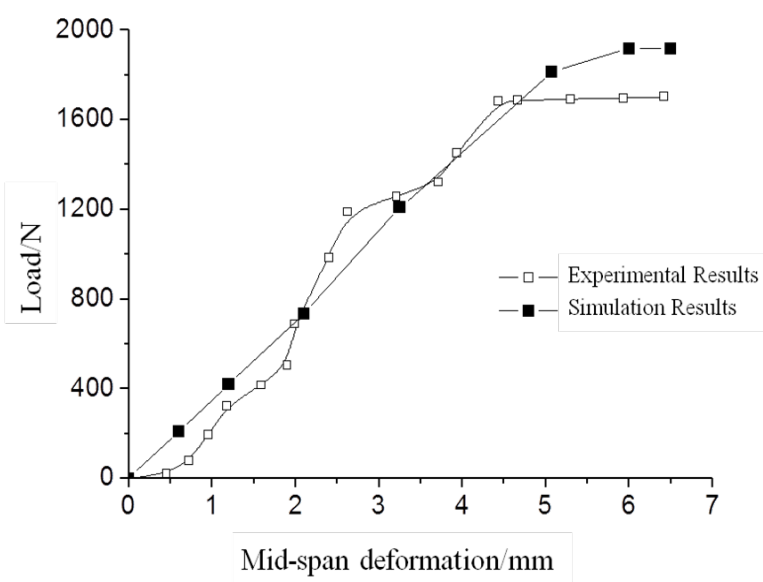

Fig.6. The curve between the load and mid-span deformation of group $2 \mathrm{~A}$ with vertical loading method

The process and results of the specimen and the simulation model with the vertical loading and the parallel loading method was shown in Fig.6 and Fig.7, respectively. The experimental results from loading to yielding, to specimen failure formed the curve between the load and mid-span deformation which had some fluctuation, which resulted from the damage of wood and reinforcing materials were gradually and the redistribution of internal force. The finite element numerical simulation results were relatively ideal. The comparison of the curve between the load and mid-span deformation showed that numerical simulation results and experimental results were basic coincide. Especially the relative error of ultimate bearing capacity and ultimate deformation is small. The results indicated that the specimen model was feasible and rational which can be used for choosing the better composite mode of the enhanced glulam.

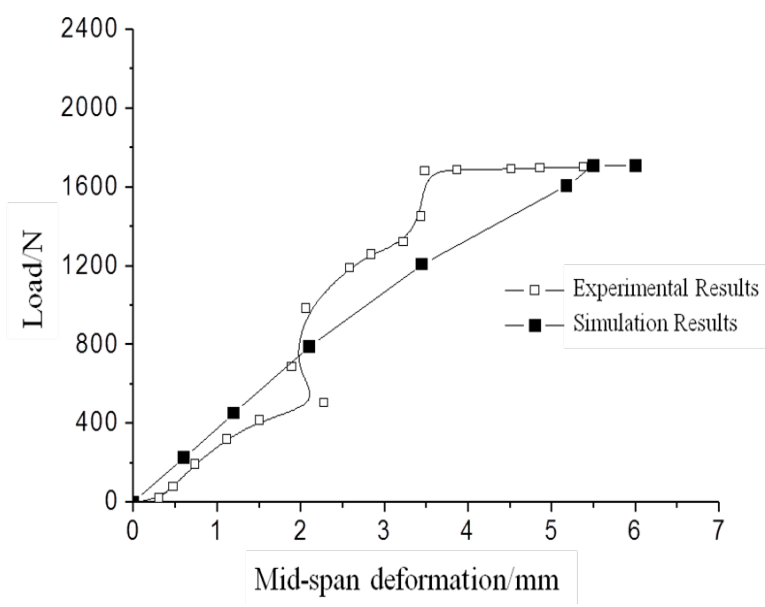

Fig. 7. The curve between the load and mid-span deformation of group 2A with parallel loading method

\section{Conclusions}

The comparison between experiment results and simulation results shows that the specimen model was feasible and rational for choosing the better composite mode and forecast the mechanical properties of glulam made up of plantation eucalyptus veneers with the reinforced materials of fiberglass mesh and aluminium foil.

The best enhanced composite structure of glulam is the central seven layers eucalyptus veneers with criss-cross assembling structure, the outer three layers eucalyptus veneers with paralleled assembling structure and fiberglass mesh and aluminum foil interval distributed among every two veneers.

\section{Acknowledgments}

This work was financially supported by the Plan Projects of Introducing Advanced International Forestry Technology (2012-4-27), the Program for New Century Excellent Talents in University (NCET-12-0725) and the Outstanding Youth Projects of Hunan Province Education Department (12B134). 


\section{References}

1. Balendra, T., Wilson, J., Gad, E., "Review of condition assessment and retrofitting techniques for timber bridge assets in Australia", Advances in Structural Engineering 13(1), 2010, pp. 171-180.

2. Hib, O., Vestl, G.I., "Modelling the variation in modulus of elasticity and modulus of rupture of scots pine round timber". Canadian Journal of Forest Research 40(4), 2010, pp. 668-678.

3. Zhou, X.Y., Li, J.H., Zhang, Z.F., "Developmental present situation and prospects analysis of modern wood frame bridge in china", Journal of Central South University of Forestry \& Technology 31(04), 2011, pp.125-130.

4. Gutkowski, R.M., McCutcheon, W.J., "Comparative performance of timber bridges", Journal of structural engineering 113(2), 1987, pp. 1468-1486.

5. Hurlbut, B.F., "Basic evaluation of the structural adequacy of existing timber bridges", Transportation Research Record (647), 1977, pp. 6-9.

6. Davids W.G., Nagy, E., Richie, M.C., "Fatigue behavior of composite-reinforced glulam bridge girders", Journal of Bridge Engineering 13(2), 2008, pp. 183-191.

7. Bakht, B., "Load distribution in laminated timber decks", Journal of Structural Engineering 114(7),1988, pp. 1551-1570.

8. Hasebe, K., Usuki, S., "Theoretical analysis and experimental study on a grillage girder using glued laminated timber", Proceedings of the Japan Society of Civil Engineers 9(397), 1988, pp. 85-94.

9. Morison, A.M., Van, K.C.D., Evensen, H.A. et al., "Dynamic response of timber bridges as a tool to measure structural integrity", Experimental Techniques 27(3), 2003, pp. 25-28.

10. Gutkowski, R.M., Favre, P.A., Natterer, J., "Laboratory tests of an anisotropic-grid timber bridge", Construction \& Building Materials 21(2), 2007, pp. 310-317.
11. Burgers, T.A., Gutkowski, R.M., Balogh, J., Radford, D.W., "Repair of full-scale timber bridge chord members by shear spiking”, Journal of Bridge Engineering 13(4), 2008, pp. 310-318.

12. Serrano, E., "Glued-in rods for timber structures - a 3D model and finite element parameter studies", International Journal of Adhesion and Adhesives, 21(2), 2001, pp. 115-127.

13. Zhang, Z.F., Zhou, X.Y., "Test on the mechanic performance of glue laminated lumber reinforced with GFRP for structural materials", Building Structure, 42(7), 2012, pp. 139-141.

14. Abe, K., Takahashi, H., Churei H., et al., "Flexural properties and shock - absorbing capabilities of new face guard materials reinforced with fiberglass cloth", Dental Traumatology 29(1), 2013, pp. 23-28.

15. Glazneva, T.S., Kaichev, V.V., Paukshtis, E.A., et al., "Structure and composition of the surface layer of $\mathrm{Zr}$-containing fiberglass materials", Journal of Non-Crystalline Solids 358(8), 2012, pp. 1053-1058.

16. Gutés, A., Carraro, C., Maboudian, R., "Silver dendrites from galvanic displacement on commercial aluminum foil as an effective SERS substrate", Journal of the American Chemical Society 132(5), 2010, pp. 1476-1477.

17. Li, M., Wang, Z.L., Wang, Z.P., et al., "The Effect of Anodizing on Adhesive Property of Aluminum Foil Mesh and Resin Matrix Composite", Materials for Mechanical Engineering (7), 2011, pp. 15.

18. Zeng, H.J., "Process for electroplating copper and tin on aluminum foil”, Electroplating \& Finishing 30(6), 2011, pp. 12-13. 